\title{
Psychosocial Interventions for Children and Adolescents after a Disaster: A Systematic Literature Review (1991-2015)
}

\author{
Mi-Sun Lee ${ }^{1}$, Jun-Won Hwang ${ }^{2}$, Cheol-Soon Lee ${ }^{3}$, Ji-Youn Kim${ }^{4}$, Ju-Hyun Lee ${ }^{5}$, Eunji Kim ${ }^{6}$, \\ Hyoung Yoon Chang ${ }^{7,8}$, Seung-Min Bae ${ }^{9}$, Jang-Ho Park ${ }^{10}$, and Soo-Young Bhang ${ }^{11}$ \\ ${ }^{1}$ Department of Psychiatry, Eulji University Hospital, Seoul, Korea \\ ${ }^{2}$ Department of Psychiatry, Kangwon National University School of Medicine, Chuncheon, Korea \\ ${ }^{3}$ Department of Psychiatry, Gyeongsang National University School of Medicine, Gyeongsang National University Changwon Hospital, \\ Changwon, Korea \\ ${ }^{4}$ Goodmind Psychiatry Clinic, Suwon, Korea \\ ${ }^{5}$ Inarae Psychiatry Clinic, Seoul, Korea \\ ${ }^{6}$ Todak Psychiatry Clinic, Ansan, Korea \\ ${ }^{7}$ Department of Psychiatry, Ajou University School of Medicine, Suwon, Korea \\ ${ }^{8}$ Sunflower Center of Southern Gyeonggi for Women and Children Victims of Violence, Suwon, Korea \\ ${ }^{9}$ Department of Psychiatry, Gachon University Gil Medical Center, Incheon, Korea \\ ${ }^{10}$ Department of Psychiatry, Ulsan University Hospital, University of Ulsan College of Medicine, Ulsan, Korea \\ ${ }^{11}$ Department of Psychiatry, Eulji University School of Medicine, Eulji University Hospital, Seoul, Korea
}

\section{재난 후 소아청소년의 정신사회적 개입: 체계적 문헌고찰(1991 2015)}

\author{
이미선 ${ }^{1}$ 황준원 ${ }^{2}$, 이철순 ${ }^{3}$, 김지연 ${ }^{4}$, 이주현 ${ }^{5}$, 김은지 ${ }^{6}$, 장형윤 $^{7,8}$, 배승민 $^{9}$, 박장호 $^{10}$, 방수영 ${ }^{11}$ \\ 을지대학교 을지병원 정신건강의학과, 강원대학교 의학전문대학원 정신건강의학교실, ${ }^{2}$ \\ 경상대학교 의학전문대학원 창원경상대학교병원 정신건강의학과, ${ }^{3}$ 좋은마음 정신건강의학과의원, ${ }^{4}$ 아이나래 정신건강의학과의원, ${ }^{5}$ \\ 마음토닥 정신건강의학과의원, ${ }^{6}$ 아주대학교 의학전문대학원 정신건강의학교실, ${ }^{7}$ 경기남부해바라기센터(거점), ${ }^{8}$ \\ 가천대학교 길병원 정신건강의학과, ${ }^{9}$ 울산대학교 의과대학 울산대학교병원 정신건강의학교실, ${ }^{10}$ 을지대학교 의과대학 을지병원 정신건강의학교실 ${ }^{11}$
}

Objective: The aim of this systematic literature review is to analyze the psychosocial interventions for children and adolescents after disasters. Methods: We conducted a review of the extant research literature from 1991 to 2015 via a comprehensive search of the MEDLINE, EMBASE, Cochrane CENTRAL, PubMed and PsyclNFO databases. The keywords employed in this research included: 'child, 'adolescent', 'youth', 'disaster', 'posttraumatic', 'psychosocial, 'therapy' and 'intervention'. The researchers followed the PRISMA guidelines. A total of 850 articles were screened for their eligibility and fifty-nine were found to meet the study criteria. The final data analysis was performed based on the disaster type, study design, type of intervention, sample size, age, school grade, number of sessions, setting of intervention delivery, providers, approach and parent involvement.

Results: Countries worldwide have experienced various kinds of disasters, including earthquakes, hurricanes, vessel accidents, tornados, tsunamis, volcanic eruptions, war, fire, terrorism, and traffic accidents. The types of psychosocial intervention that were conducted after these disasters included: psychological first aid, psychological debriefing, psychoeducation, trauma focused cognitive behavior therapy, eye movement desensitization reprocessing, prolonged exposure therapy, group play therapy and arts therapy, project interventions, school-based interventions and web-based interventions.

Conclusion: The findings of the systematic literature review suggest that an appropriate psychosocial intervention could be utilized as evidence-based mental health treatment for children and adolescents after disasters.

Key Words: Disaster; Trauma; Psychosocial intervention; Children adolescent; Systematic literature review.

Received: May 27, 2016 / Revision: August 2, 2016 / Accepted: October 13, 2016

Address for correspondence: Soo-Young Bhang, Department of Psychiatry, Eulji University School of Medicine, Eulji University Hospital, 68 Hangeulbiseok-ro, Nowon-gu, Seoul 01830, Korea

Tel: +82-2-970-8303, Fax: +82-2-970-8429, E-mail: dresme@dreamwiz.com

This is an Open Access article distributed under the terms of the Creative Commons Attribution Non-Commercial License (http://creativecommons.org/licenses/by-nc/3.0) which permits unrestricted non-commercial use, distribution, and reproduction in any medium, provided the original work is properly cited. 


\section{서 론}

소아청소년은 성장하면서 성인이 되기 전까지 여러 외상 사 건에 노출된다. 한 종단 연구에 따르면 소아청소년의 $68.8 \%$ 는 16 세 이전에 하나 이상의 외상적 사건에 노출되며, 가족이나 또래의 외상 경험( $62 \%)$, 가족이나 또래의 갑작스러운 죽음 (60\%), 폭행(38\%), 교통사고(28\%), 자연 재해(지진, 토네이도, 화재, 홍수 등)(17\%) 등을 경험한다. ${ }^{1)}$ 외상 사건에 노출된 이후 소아청소년이 경험하는 정신심리학적 증상은 발달 단계에 따 라 다양한 형태를 보이게 되고, 관련된 증상의 보고 역시 인지 적 발달 수준에 따라 제한적일 수 있다. ${ }^{2)}$ 특히 소아청소년기의 외상은 외상 후 스트레스 장애(post traumatic stress disorder, $\mathrm{PTSD}$ ), 품행 장애, 주요 우울 장애, 주의력 결핍 과잉 행동 장 애, 해리 장애 및 적응 장애 등의 주요 정신 장애뿐 아니라 경 계성 인격 장애, 자기애성 인격 장애와 같은 인격 장애로도 발 전할 수 있으며 ${ }^{2}$ 취약한 소아청소년은 증상의 악화로 인하여 지속적인 어려움을 겪을 수 있다.)

그러므로 심리적 외상을 경험한 소아청소년들에게 있어 정 신심리적 문제를 예방하기 위해서는 적절한 평가와 개입이 필 요하다. ${ }^{45)}$ 사고나 재난이 발생하지 않았을 때는 관계자와 전 문가 훈련 등의 준비를 통하여, 재난 발생 이후 급성 단계에서 는 즉각적으로 심리사회적 개입 및 지원이, 아급성 단계에서 는 심리회복기술훈련(skills for psychological recovery)과 전 문화된 정신치료 등을 제공할 수 있도록 하는 것이 필요하다. 이후 지속적인 치료가 필요한 경우에는 적절한 지역사회의 의 료 및 심리 서비스를 받을 수 있도록 자원을 연결하게 된다.

본 논문의 저자 중 일부는 2015년 본 논문집을 통하여 소 아청소년에서의 재난 이후 시기에 따라 재난 전 단계, 재난 직 후 급성기 단계, 재난 후 아급성기 단계 각각에서의 개입 방법 에 대한 문헌을 고찰하였다. ${ }^{6}$ 그러나 개입 방법들에 대한 효 과 수준을 비교하지는 못하였다. 따라서 본 논문에서는 사고 및 재난 이후 급성기, 아급성기에 있어 지역사회 및 학교 현장 에서 할 수 있는 개입 방법 중 개입의 효과가 동료심사(peer review)를 거쳐 출판된 논문 보고들을 체계적 문헌고찰을 통 하여 개입 종류별로 구분하고, 개입의 효과에 대한 보고를 중 점적으로 보고자 한다. 이를 통하여 사고나 재난 이후 각 시기 마다 효과가 보고된 근거 있는 개입들을 선정하는 데 기여하 고자 하였다.

\section{방 법}

MEDLINE, EMBASE, Cochrane CENTRAL, PubMed, PsyclNFO의 데이터베이스 검색을 통해 1991년부터 2015년까
지의 포괄적인 국외 소아청소년 재난 치료 개입 연구문헌들을 검토하였다. 검색어는 'child', 'adolescent', 'youth', 'disaster', 'posttraumatic, 'psychosocial, 'therapy', 'intervention'의 medical subjects headings 키워드를 포함하여 검색을 실시하였다. 문헌 선정 흐름도는 "preferred reporting items for systematic reviews and meta-analyses의 보고 지침'에 따라 검색, 선별, 선정단계를 거쳤다(Fig. 1). 최종 데이터베이스와 웹 검색을 통 해 중복된 문헌을 제거한 이후, 제목 및 초록을 식별하여 연 구의 적합성을 평가하였으며, 이후 선별된 문헌은 전체 논문 내용을 분석하고 선정 기준 및 배제 기준에 따라 분류하였다.

선정 기준은 본 연구 주제와의 적합성, 연구결과의 명확성, 정신사회적 개입 여부, 영어로 발표된 연구에 한하였으며, 제 외 기준은 연구결과의 불확실성, 비영어권 언어로 발표된 문 헌, 소아청소년을 대상으로 하지 않는 연구, 주제와 관련성이 적은 연구, 종설 및 보고서는 제외하였다. 이에 따라 체계적 문헌고찰을 수행할 최종 연구문헌을 선정하였으며, 두 명의 연구자 간 합의 및 공동 연구원의 자문을 통해 의견 통합을 이루었다. 최종 문헌 자료들은 치료 개입 유형, 재난 구분, 연 구 설계, 대조군 유무, 연구 대상, 집단 및 개인여부, 연구 대상 수, 연령, 치료 기간, 치료 제공 주체, 학부모 참여 여부 등의 기준으로 분류한 선행연구7,8)를 바탕으로 본 연구자료 분석을 시행하였다. 연구결과는 연구 시행 시기 및 재난의 종류, 대조 군 유무에 따른 근거 수준을 기준으로 순서대로 기술하였다.

\section{결 과}

다양한 재난(지진, 허리케인, 선박사고, 토네이도, 쓰나미, 화 산폭발, 전쟁, 화재, 테러, 교통사고 등) 사고 발생 이후, 정신사 회적 개입으로 적용된 치료 프로그램으로는 심리적 응급지원 (psychological first aid, PFA), 심리적 디브리핑(psychological debriefing), 심리교육(psychoeducation), 외상초점인지행동치 료(trauma focused cognitive behavior therapy, TF-CBT), 안 구운동 민감소실 및 재처리 요법(eye movement desensitization reprocessing, EMDR), 지속적 노출치료(prolonged exposure therapy, PE), 집단 놀이치료 및 예술치료(group play therapy and arts therapy), 프로젝트 개입(project intervention), 학교기 반 개입(school-based intervention), 웹 기반 개입(web-based intervention), 그 외 등이 있었다. 분석 결과는 일반적인 개입 과 지역사회나 학교와 같이 특화된 상황에 대한 개입으로 나 누어 기술하였다(Table 1).

\section{특정 지역사회나 학교 등에 대한 특화된 개입이 아닌 경우}

다음은 특정 지역사회나 학교와 같이 특정 장소에 적합하 


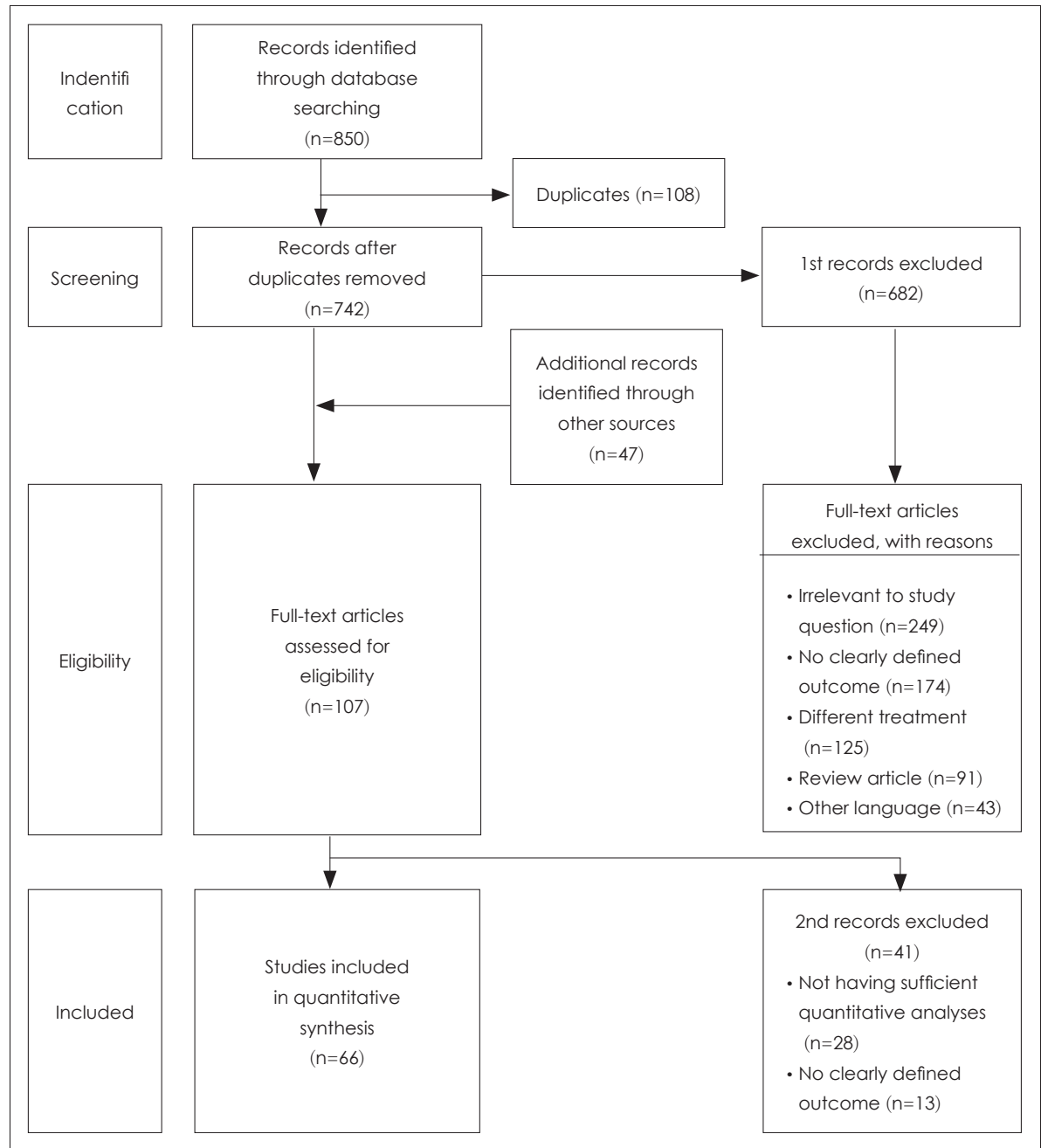

Fig. 1. Flow of studies through the systematic review process.

도록 구성한 것이 아니라 어디서든 실시할 수 있도록 개발된 개입 방법으로, 주로 개인 및 소규모 집단을 설정하여 개입한 방법들을 기술하였다.

\section{심리적 응급지원(Psychological first aid, PFA)}

$\mathrm{PFA}$ 는 재난 직후 피해자의 기본적인 의료·정신·사회적 욕 구를 해결하기 위한 정보 및 실질적인 자원을 제공하고 안전 과 유대감에 기반을 둔 개입이다. 일반적으로 $\mathrm{PFA}$ 를 제공하 는 것은 재난 피해 집단의 중요한 예비 접근 방식으로서, 재 난 대응 시 필요한 연락처, 안전 및 편의, 안정화, 실제적 지원, 자원 대처, 정보 수집 및 서비스 연결 등의 요소들로 구성되 어 있다.")

소아청소년을 대상으로 PFA를 적용한 연구들을 살펴보면, 2005년 허리케인 카트리나(Katrina) 사건 발생 이후, Cain 등이 과 Plummer 등 ${ }^{11)}$ 의 연구에서는 초등학생과 중학생을 대상으 로 PFA를 시행하였다. 이들 연구는 대조군 설정이 없는 연구
로서 정신건강전문가가 치료 제공 주체가 되어 6주에 해당하 는 PFA를 제공하였다. Cain 등이의 연구에서는 5 15세의 소 아청소년 99명에게 개별적으로 PFA를 시행하였고, PTSD 증 상이 유의하게 호전되었다. Plummer 등믄 6 15세의 소아 청소년 12 명에게 집단으로 PFA를 시행하였고 연구 대상의 자 기보고식 참여 만족도 평가에서 긍정적인 결과가 나타났다. 우리나라에서는 현재까지 소아청소년을 대상으로 한 PFA를 적용한 개입의 효과가 보고된 바는 없다(부록 1).

\section{심리적 디브리핑(Psychological debriefing)}

심리적 디브리핑은 재난 이후 생존자들이 자발적으로 사건 에 대한 자신의 경험 및 반응을 공유하고, 사건을 재구성하며 대처 전략을 논의하는 집단 위기 개입을 의미한다. ${ }^{12)}$ 이 때, 소아청소년의 경우에는 자발적 참여 및 부모의 동의가 필요 하다. ${ }^{13)}$ 소아청소년에서의 심리적 디브리핑은 또래자살사건, ${ }^{14}$ 교통사고, ${ }^{13,15)}$ 학교 인질극 ${ }^{16)}$ 선박사고 ${ }^{1718}$ 와 같은 재난 유형에 
Table 1. Types of intervention

\begin{tabular}{|c|c|}
\hline Types & Intervention details \\
\hline PFA (Appendix 1) & Psychological first aid \\
\hline \multirow[t]{2}{*}{ Psychological debriefing (Appendix 2) } & Debriefing \\
\hline & Debriefing and CBT \\
\hline \multirow[t]{3}{*}{ Psychoeducation (Appendix 3) } & Emergency hazard education \\
\hline & Psychoeducation and interpersonal CBT \\
\hline & Psychosocial intervention \\
\hline \multirow[t]{6}{*}{ TF-CBT (Appendix 4) } & Cognitive therapy \\
\hline & Cognitive-behavioral intervention \\
\hline & Cognitive behavior therapy (CBT) \\
\hline & CBT with grief intervention \\
\hline & Behaviourally-based intervention \\
\hline & Trauma-focused early intensive cognitive behavioral intervention \\
\hline EMDR (Appendix 5) & Eye movement desensitization reprocessing (EMDR) \\
\hline \multirow[t]{2}{*}{ PE (Appendix 6) } & Adapted prolonged exposure (PE-A) \\
\hline & Narrative and exposure therapy for children \\
\hline \multirow{3}{*}{$\begin{array}{l}\text { Group play therapy and arts therapy } \\
\text { (Appendix 7) }\end{array}$} & Play therapy \\
\hline & Arts therapy (drawings, accident-related toys) and psychoeducation \\
\hline & Arts therapy (storytelling, drawing, free play and role-play) \\
\hline \multirow[t]{6}{*}{ Other interventions (Appendix 8) } & Community-based grief and trauma intervention (GTI) \\
\hline & GTI with coping skills and trauma narrative processing \\
\hline & Client centered therapy \\
\hline & Catastrophic stress intervention \\
\hline & Massage \\
\hline & Spiritual hypnosis \\
\hline \multirow[t]{4}{*}{ Project intervention (Appendix 9) } & Baton rouge children's health project \\
\hline & Carolina adolescent health project \\
\hline & Multi-modality trauma treatment \\
\hline & The start treatment protocol \\
\hline \multirow[t]{15}{*}{ School-based intervention (Appendix 10) } & Cognitive behavioral intervention for trauma in schools \\
\hline & Teacher-delivered protocol focusing on enhancing personal resilience \\
\hline & Classroom-based intervention \\
\hline & Enhancing resiliency amongst students experiencing stress (ERASE-Stress) \\
\hline & ERASE-Stress-Sri Lanka \\
\hline & Objective exposure to terrorism \\
\hline & School-based trauma-specific intervention \\
\hline & School reactivation program \\
\hline & School social work service \\
\hline & School therapeutic enhancement program \\
\hline & School-based community-wide screening followed by psychosocial intervention \\
\hline & School-based mental health intervention \\
\hline & School-based test anxiety intervention \\
\hline & Teacher-based intervention \\
\hline & Teacher-mediated intervention \\
\hline \multirow[t]{2}{*}{ Web-based intervention (Appendix 11) } & Bounce back now (BBN) \\
\hline & BBN plus adult self help module \\
\hline
\end{tabular}

TF-CBT: trauma focused CBT, PE: prolonged exposure therapy 
서 보고되고 있다.

Poijula 등 ${ }^{14}$ 의 연구에서는 14 17세의 소아청소년 89명을 대상으로 또래자살사건이 있었던 학교에서 정신건강전문가가 1 회기 디브리핑을 제공하였으며, 6 주와 10 개월 후 추적관찰을 실시한 결과, 적절한 위기 개입은 학교에서의 자살 전염을 방 지하는 데 효과가 있었다. Stallard와 $\mathrm{Law}^{15)}$ 는 버스 사고를 경 험한 14 16세 소아청소년 7명에게 2주간의 디브리핑 교육을 진행하였고, 개인치료와 집단치료를 병행하였다. 또한 필요 시 가족에 대한 개입을 함께 실시한 결과, 사후 평가에서 생존자 들의 PTSD 증상에 상당한 개선이 있었다. Stallard 등ㄱㅇㅢ 의 연 구에서는 교통사고 후, 7 18세의 소아청소년 158명을 대상으 로 1 회기의 집단 디브리핑을 시행한 결과, 후속평가에서 심리 적 증상이 호전되었으나, 자연적 회복과 비교해서 더 효과가 입증되지는 않았다. Vila 등흐는 프랑스 파리의 한 학교 인질극 사건 이후, 6 9.5세의 소아청소년 26명을 대상으로 6주 동안 총 24시간에 해당하는 디브리핑을 실시하였고 이때 대상자들 의 부모도 모두 참여하도록 하였다. 소아 상태 특성 불안척도 (State and Trait Anxiety Inventory for Children)와 개정판 사 건 충격 척도(Revised Impact of Event Scale, IES-R)를 사용 하여 평가하였으며, 그 결과 심리적 디브리핑은 외상 후 스트 레스 장애 발생을 방지하기에는 부족한 부분이 있었으나 디 브리핑을 시행하지 않은 대조군에 비해 유의한 호전을 나타 냈다. Yule과 Udwin ${ }^{17)}$ 의 연구에서는 1988년 발생한 주피터 (Jupiter) 선박사고 개입에 대해 보고하였는데, 14 16세 소아청 소년 24명에게 교내에서 정신건강전문가가 1 회기의 집단 디브 리핑을 실시하였다. 그리고 Yule ${ }^{18)}$ 은 동일한 주피터(Jupiter) 선박사고 이후 14 16세의 소아청소년 39명을 대상으로 디브 리핑 1회기 및 집단 CBT 2회기를 병행한 치료 방법을 제시하 였으며, Birleson 우울 척도(Birleson Depression Scale, BDS), 개정판 소아 발현 불안척도(Revised Children's Manifest Anxiety Scale, RCMAS), 사건 충격 척도(Impact of Event Scale) 를 실시하여 이에 대한 긍정적인 결과가 나타났다. 한편 심리 적 디브리핑이 단일 세션으로서 PTSD 발병 예방, 스트레스, 우울증 또는 불안 증상을 상대적으로 감소시키지 못한다는 연구결과 ${ }^{19)}$ 와 재난 직후 감정적 마비 상태인 소아청소년에게 즉각적으로 심리적 디브리핑을 시행해야 할 근거가 아직 부족 하다는 연구보고 ${ }^{20)}$ 가 있으므로, ${ }^{6}$ 피해자의 정신건강 위기 개 입에 효과적이지 않을 수 있어 디브리핑을 계획할 때는 신중하 게 실시 여부를 판단하는 것이 필요하다(부록 2).

\section{심리교육(Psychoeducation)}

심리교육은 외상 사건의 여파로 인한 심리적 반응에 대한 교육이다. 여기에는 외상 경험에 대한 의견 공유, PTSD 치료
법 안내, 스트레스 대처법 및 치료 목표에 대한 논의 등이 포 함되며 면담을 통해 환자에게 재난 경험에 대한 인식과 대응 체계를 제공한다. ${ }^{21)}$ 심리교육은 재난 이전의 위험 대비 교육 ${ }^{22}$ 과 재난 발생 이후 개입 ${ }^{23-25)}$ 으로 구분하여 살펴볼 수 있다.

재난 이전 위험 대비 교육으로 교사와 학교 관계자가 11 13 세 소아청소년 219명을 대상으로 학교에서 6주의 집단 심리교 육을 실시한 연구가 있었다.2) 재난 후 심리교육을 단독으로 진행한 연구는 찾아보기 어려운데, 1999년 터키 지진 사건 이 후 774명에 해당하는 소아청소년을 대상으로 교사가 교내 심 리교육을 실시한 바 있으며, 이때 부모가 함께 참여한 보고가 있다. ${ }^{24)}$ 해당 연구결과, 부모와 자녀가 재난 이후 발생한 심리 적 반응에 대해 충분히 이해하였고 추후 만족도 평가에서도 효과가 있었다고 보고하였다. Vijayakumar 등 25)은 인도양 지 진 해일 재난에 대한 연구에서 교내 학생 135명(11 14세)에게 6 회기의 집단 심리교육을 시행하였고, 청소년 자기보고 척도 (Youth Self Report) 및 아동 행동평가 척도(Child Behavior Check List, CBCL)를 실시한 결과, 학생들의 과잉 행동 문제 가 감소되었다 $(\mathrm{z}=2.41, \mathrm{p}=0.016)$ 고 보고하였다. Goenjian 등 23$)$ 은 1988년 아르메니아에서 발생한 지진 이후, 15 17세 소아청 소년 63명을 대상으로 정신건강전문가가 교내 심리교육과 대 인관계 인지행동치료(interpersonal CBT)를 시행한 결과를 보고하였다. 이들은 3 주 동안 개인치료 2 회기와 집단치료 4 회 기를 실시하였고, 소아 외상 후 스트레스 장애 척도(Child Posttraumatic Stress Disorder Reaction Index, CPTSD-RI)와 우울증 자기보고 척도(Depression Self-Rating Scale, DSRS) 를 사용하였으며 개입 후, 심한 외상에 노출된 소아청소년의 $\mathrm{PTSD}$ 증상과 우울 증상을 감소시키는 데 유의한 효과가 있었 다. 요약하면 심리교육은 대개 재난 후 학교에서 집단으로 실시 되었고, 다른 개입에 통합하여 실시된 것을 알 수 있다(부록 3).

\section{심리회복기술훈련(Skills for psychological recovery, SPR)}

심리회복기술훈련(skills for psychological recovery, SPR) 은 재난 발생 시 PFA 이후, 외상 사건에 노출된 소아청소년, 성인, 가족의 심리적 회복을 위해 개발된 기술훈련 개입이다. $\mathrm{SPR}$ 모듈은 문제 해결, 신체 및 감정 반응 다루기, 긍정적 활 동 계획하기, 도움되는 생각하기, 건강한 사회적 관계 재구축 하기 등의 요소들을 포함한다. ${ }^{26)}$ 이 훈련은 다양한 재난(허리 케인, 토네이도, 지진, 홍수 등) 상황에서 적용 가능한 위기 상 담 서비스 프로그램으로서 정신건강 실무자를 대상으로 한 교육 연구 ${ }^{27)}$ 는 발표되었으나, 현재까지 국내 및 국외에서 소아 청소년을 대상으로 한 SPR 개입 효과는 보고된 바 없다. 


\section{외상초점인지행동치료(Trauma focused cognitive behavior} therapy, TF-CBT)

$\mathrm{TF}-\mathrm{CBT}$ 는 외상에 초점을 둔 심리교육 및 부모 교육, 이완 과 정서 조절, 인지적 대처능력 이해, 외상 이야기 치료, 외상 의 인지적 처리, 안전 강화 및 미래에 대한 전략 세우기 등의 구성 요소를 포함하는 인지행동치료 개입이다. ${ }^{28)} \mathrm{TF}-\mathrm{CBT}$ 를 적용한 연구들은 이 논문에서 다루는 재난 이후의 소아청소 년에 대한 심리사회적 개입들 중에서 대조군 연구들을 포함 하여 가장 많은 연구 보고가 이루어져 왔다.

Ronan과 Johnston ${ }^{29}$ 은 1995년 뉴질랜드 루아페후 산 (Mount Ruapehu)의 화산폭발 사건과 관련하여 소아청소년 113명(7 13세)에게 행동치료에 기반한 개입을 적용하고, CPTSD-RI 척도와 대처능력 질문지(coping questionnaire) 로 평가한 결과, 소아청소년의 PTSD 증상과 대처능력 요인이 유의하게 개선되었다고 보고하였다. Karairmak와 $\mathrm{Aydin}^{30}$ 은 1999년 터키 마르마라(Marmara) 지역의 지진 사건 당시, 초등 학생을 대상으로 3주간 9회기의 인지치료(cognitive therapy) 를 실시하였다. 치료 목표는 실험군과 대조군에서 소아 두려움 설문 평가지(Modified version of the Fear Survey Schedule for Children)를 사용하여 불안과 공포를 관찰하도록 설정하 였으며, 대상자의 부모도 함께 참여시켰다. 연구결과, 여아가 남아에 비해 불안이 더 높았고, 실험군은 불안 증상에서 유 의한 효과가 없었으며, 대조군에서는 공포 증상이 감소되었다 고 보고하였다. 1999년 그리스 아테네 지진 사건에 대해 Giannopoulou 등 ${ }^{31}$ 은 8 12세의 소아청소년 17명을 대상으로 교내에서 집단 $\mathrm{CBT}$ 를 6주 동안 실시하였다. 연구결과, 침습, 회피, 각성, 우울, 심리적 기능 수준에서 유의한 개선이 있었 다. 2000년 네덜란드 엔스헤데(Enschede) 지역에서는 불꽃놀 이 공장 폭발사고가 발생하였고, 이 사고에 노출된 4 18세의 소아청소년 52명에 대한 연구리가 있었다. 이 연구에서 실험집 단에게는 $\mathrm{CBT}$ 를, 대조집단에게는 $\mathrm{EMDR}$ 을 적용하였으며, 3 개월의 추적관찰 결과 UCLA PTSD 척도(The UCLA PTSD Reaction Index, PTSD-RI), 소아용 외상 후 증상 척도(The Child Report of Post-Traumatic Symptoms), 부모용 외상 후 증상 척도(The Parent Report of Post-Traumatic Symptoms), Birleson 우울 척도(BDS), 소아 다차원 우울 척도(The Multidimensional Anxiety Scale for Children), CBCL 척도를 통 해 두 집단 모두 PTSD 증상, 우울, 불안 및 행동 문제가 감소 되었다고 보고하였다.

Naderi 등 ${ }^{33}$ 의 연구에 따르면, 2003년 이란 지진 사건을 경 험한 11 18세 소아청소년 85명에게 학교와 공원 내 이동식 주 택에서 $\mathrm{CBT}$ 를 4주 동안 실시하였다. 이에 대한 결과로 외상 후 스트레스 척도(Post Traumatic Stress Scale, PSS)를 통해
대상자의 PTSD 증상과 회피증상에서 평균 점수가 감소되었 으나, PTSD 재경험 및 과다 각성 증상에서는 변화가 없었다. Shooshtary ${ }^{34)}$ 는 동일한 이란 지진에 노출된 11 20세 소아청 소년 168 명을 대상으로 4 회기의 $\mathrm{CBT}$ 를 학교 및 정신건강전 문기관에서 실시한 결과, IES-R 척도에서의 PTSD 증상(침 습, 회피, 각성)을 완화시키는 데 효과가 있음을 입증하였다. 이 외에 6 11세 소아청소년 161명을 대상으로 CBT, CBT와 예술 및 체육 활동, 예술과 체육 활동, 무처치 대조군으로 나 누어 개입 결과를 비교· 분석한 연구 ${ }^{35}$ 에서는 반구조화된 면담 (Kiddie-Schedule for Affective Disorders and SchizophreniaPresent and Lifetime Version, K-SADS-PL)을 통해 CBT와 예술 및 체육 활동 개입이 소아청소년의 PTSD 증상을 감소시 키는 데 효과가 있었다고 보고하였다. March 등 ${ }^{36}$ 은 교통사고, 심한 폭풍, 총기 부상, 심각한 질병, 화재 사건 등의 경험이 있 는 10 15세 소아청소년 17명을 대상으로 집단 CBT 프로토콜 을 기반으로 한 외상 치료(multi-modality trauma treatment, MMTT) 프로젝트를 시행하였다. MMTT는 교내에서 실시한 18 주의 집단 프로젝트로서 DSM-IV PTSD을 통해 구조화된 면담을 실시하였으며, 사전·사후 연구결과 소아청소년의 우울, 불안, 분노 증상이 유의하게 개선되었다.

2001년 미국의 9/11 이후 진행된 여러 연구가 있다. Brown 등 ${ }^{37}$ 은 사건에 노출된 5세 소아에게 인지행동치료와 더불어 애도 개입(grief interventions)을 병행하였다. 정신건강전문 기관에서 개인치료와 집단치료가 16 주에 걸쳐 시행되었고, 부 모가 평가와 치료에 모두 참여하였다. 9/11 테러 사건 이후, 소 아청소년의 트라우마 치료 및 서비스 컨소시엄(the child and adolescent trauma treatments and services consortium, $(\mathrm{CATS})^{38}$ 의 연구에서는 5 21세 소아청소년 306명을 대상으 로 실험집단은 TF-CBT 8 20회기를, 대조집단은 간략한 인 지행동치료 기술(brief-CBT skills) 개입을 4회기 실시하여 비 교· 분석하였다. 6 개월 후, 두 집단의 증상 심각도는 차이가 있 었으나 양 군에서 PTSD 증상은 유의하게 호전되었다. CATS 에서의 또 다른 연구 ${ }^{39}$ 에서는 소아청소년 700 명을 대상으로 $\mathrm{CBT}$ 를 개인치료와 집단치료로 나누어 시행하였다. 이는 $9 / 11$ 테러와 관련된 가장 큰 규모의 개입으로, 인지행동치료 결과 소아청소년의 PTSD 증상이 유의하게 개선되었다.

미국에서 9/11 이후 진행된 트라우마에 관한 연구와 이에 따른 개입에 대한 훈련은 이후에 재난 이후 개입을 미리 준비 하게 되는 계기가 되었다. 2005년 미국의 허리케인 카트리나 (Katrina)로 인한 피해 이후 소아청소년에 대한 개입과 관련 한 보고들을 살펴보더라도 이를 확인할 수 있다. 허리케인 카 트리나(Katrina)로 인한 피해 이후 Scheeringa 등 ${ }^{40)}$ 은 3 6세 소아청소년 64명에게 집단 TF-CBT 12회기를 실시하였다. 사 
전-사후 검사결과, 대조군에 비해 $\mathrm{PTSD}$, 우울, 분리불안, 반 항성장애 요인에서 유의한 효과가 있었다. 동일한 사건에 대 하여 Cohen 등근 은 11세 소아청소년을 대상으로 TF-CBT와 학교 내 외상 인지행동치료 개입(cognitive behavioral intervention for trauma in schools, CBITS)을 병행하였다. TFCBT는 12 16회기의 개인치료로 구성되었고, CBITS는 개인 치료 1 3회기와 집단치료 10 회기로 구성되었다. 정신건강전문 가와 교사가 치료를 실시하였으며, 부모가 참여하였다. 치료 종결 후, 연구 대상은 심리적 안정감이 유지되어 더 이상 악몽 을 꾸지 않았다고 보고하였다. Jaycox 등 는 허리케인 카트리 나(Katrina) 사건과 관련하여 4 8세의 소아청소년 118명을 대상으로 TF-CBT와 TF-CBITS를 비교한 연구를 보고하였 다. 연구결과, $\mathrm{K}-\mathrm{SADS}$ 면담에서 두 집단 모두 우울 증상에서 변화가 나타났으나, 통계적으로는 TF-CBITS 집단에서 보다 유의한 호전이 나타났다. 또한 Taylor와 Weems ${ }^{411}$ 는 허리케인 카트리나(Katrina) 발생 이후, 8 13세의 소아청소년 6명에게 인지행동치료를 활용한 집단 프로젝트(The StArT treatment protocol, StArT)를 진행하였다. StArT는 소아청소년의 PTSD 증상 개선을 위해 국립 센터의 후원으로 개발된 매뉴얼이며, 그 결과 PTSD, 불안, 우울 증상이 유의하게 호전되었다.

Pityaratstian 등 ${ }^{42}$ 의 보고를 보면 2004년 태국 쓰나미 사건 발생 이후, 9 15세 소아청소년 160명에게 이틀 동안 CBT를 집단으로 시행하였는데, 소아 사건 충격 척도(The Children's Impact of Events Scale-13)를 실시한 결과 PTSD 증상 완화 에 유의한 효과가 있었다. 이스라엘의 자살 폭탄공격 사건 이 후, Leor 등 ${ }^{43)}$ 은 10 명의 소아청소년에게 개인치료와 집단치료 를 병행한 외상초점의 초기 집중 인지행동치료(trauma-focused early intensive cognitive behavioral intervention, TF-EICBI) 를 시행하였고, DSM-III-R에 의한 구조화된 임상 면접(Structured Clinical Interview for Axis 1 DSM-III-R Disorders)과 $\mathrm{CBCL}$ 척도를 실시한 결과 연구 대상의 외상 후 스트레스 증 상을 감소시키는 데 효과가 있었다.

기타 학교 환경에서 개입한 연구에 대해서는 뒷부분의 학교 기반 개입 부분에서 자세히 다루고자 한다(부록 4).

\section{안구운동 민감소실 및 재처리 요법(Eye movement desensitization reprocessing, EMDR)}

$\mathrm{EMDR}$ 은 외상과 관련된 고통스러운 기억의 이미지와 감각 을 식별하고, 양측성 자극인 안구운동을 통해 기억을 재처리 하도록 돕는 치료이다. EMDR은 본래 성인 PTSD 치료를 위 해 개발되었으나, PTSD 이외의 병리적 문제나 복합 외상을 겪 는 소아청소년 치료에도 적용되고 있다.

Chemtob 등 ${ }^{44}$ 은 1992년에 발생한 하와이 허리케인 이니키
(Iniki) 사건 이후 PTSD 증상을 지속적으로 보인 6 12세 소 아청소년 32명을 대상으로 EMDR 개입을 시행하였다. 정신 건강전문가가 교내에서 진단 1 회기 및 $\mathrm{EDMR} 3$ 회기를 진행하 였고 개인치료와 집단치료를 병행하였다. 6개월의 추적관찰 결과, 소아 반응 척도(Child Reaction Index), 소아 우울 척도 (Children's Depression Inventory, CDI), RCMAS 척도 평가 에서 유의한 호전을 보였다.

Fernandez ${ }^{45}$ 는 이탈리아 몰리세(Molise) 지역의 지진 사건 을 경험한 7 11세 소아청소년 22명에게 평균 6.5회기의 집단 EMDR 치료를 1년 이상 실시하였고, 소아 PTSD 설문(list of typical PTSD symptoms)을 시행한 결과, PTSD 증상(회피, 침습, 각성)을 감소시키는 데 효과가 있었다(부록 5).

\section{지속적 노출치료(Prolonged exposure therapy, PE)}

$\mathrm{PE}$ 는 치료에 대한 기대 목표 설정, 횡격막 호흡과 점진적 근육 이완 훈련, 외상에 대한 일반적 반응 교육, 가상적 노출, 처리, 숙제에 대한 교육 등으로 이루어진 개입이다. ${ }^{46}$ 그리고 외상 사건에 대한 노출 처리를 시행하면서 환자가 경험한 상 황, 생각, 이미지, 느낌 등 자극에 대한 공포 반응을 감소시키 는 것을 목표로 한다. ${ }^{47)}$

성인을 대상으로 한 연구 ${ }^{47)}$ 에서는 PE가 환자의 우울, 불안, 죄책감, 분노, 사회적 기능 요인을 포함한 PTSD 증상에 유의 한 효과가 있다고 보고하였으나, 소아청소년을 대상으로 한 $\mathrm{PE}$ 연구는 현재로서는 소수이다.

Gilboa-Schechtman 등 ${ }^{48}$ 은 이스라엘에서 테러 공격, 자동 차사고, 성폭행 등을 경험한 12 18세의 소아청소년 38명을 대상으로 K-SADS-PL 면담을 실시하였으며, 실험군은 PE 12 15회기, 대조군은 정신역동치료 15 18회기를 시행하여 비 교·분석하였다. 그 결과, $\mathrm{PE}$ 개입은 정신역동치료에 비하여 $\mathrm{PTSD}$ 증상과 우울 증상에서 효과가 있었으며, 6개월 및 17 개월의 추적관찰에서 치료적 효과를 유지하였다. 스리랑카의 인도양 지진 해일 사건에 대한 Catani 등 ${ }^{49}$ 의 연구에서는 재 난을 경험한 8 14세 소아청소년 31명에게 이야기 노출치료 (narrative exposure therapy for children) 6회기를 2주 동안 실시하였다. 6개월의 추적관찰 결과, PTSD-RI 척도를 통해 대상자의 PTSD 증상이 감소되었고 심리적 안정감이 유지되 었다(부록 6).

\section{집단 놀이치료 및 예술치료(Group play therapy and arts} therapy)

집단 놀이치료 및 예술치료는 창조적인 예술적 과정(놀이, 미술, 음악, 동작, 연극 등)을 통해 비언어적 의사소통, 감정 표 현, 자기 발견, 카타르시스를 경험하는 개입이다. 이러한 심리 
치료적 예술 작업은 개인의 성장을 도모하고 부정적인 심리 적 증상들을 완화시킨다. ${ }^{50)}$

Shen ${ }^{511}$ 의 연구에서는 1999년 대만 지진 사건에 노출된 8 12 세 소아청소년 30 명을 대상으로 집단 놀이치료 10 회기를 실 시하였다. 집단 놀이치료는 교내에서 정신건강전문가가 개입 하고 부모가 참여하였으며, 레이븐 컬러 표준 도형 지능 검사 (The Raven's Coloured Progressive Matrices Test)와 스펜스 소아 불안척도(The Spence Children's Anxiety Scale)로 평가 하였다. 그 결과 소아청소년의 자살 위험 및 불안 수준이 유 의하게 호전되었다 $(\mathrm{p}<0.05)$. Zehnder 등 ${ }^{52}$ 의 연구에서는 교 통사고 경험이 있는 7 16세 소아청소년 99명에게 예술치료(그 림 그리기, 사고와 관련된 장난감 놀이) 1 회기를 실시하였다. 심리교육을 함께 병행하여 부모가 함께 참여하였고, 소아청소 년 외상 후 증후군 척도(Clinician-Administered PTSD Scale for Children and Adolescents), 소아 우울 척도(CDI), CBCL 척도를 평가하였으며, 연구결과 사춘기 이전 소아청소년의 우 울 증상 및 문제 행동이 감소되었다고 보고하였다. 한편으로, Thabet 등 53)은 이스라엘의 지속적인 전쟁 분쟁이 발생하는 가 자 지구(Gaza Strip) 난민캠프에서 9 15세 소아청소년 111명 을 대상으로 교사와 학교 관계자가 집단예술치료를 7주 동안 진행하였다. 스토리텔링, 그림 그리기, 자유놀이와 역할극 등 을 주제로 활동하였으며, 사전-사후 결과 CPTSD-RI 척도와 $\mathrm{CDI}$ 척도를 통해 본 외상 및 우울 증상에서는 유의한 효과가 없었다(부록 7).

\section{기타 개입(Other interventions)}

보고된 연구가 소수여서 기타로 분류된 경우는 다음과 같 은 개입법들이 있다: 1) 애도와 트라우마 개입(grief and trauma intervention, GTI, 2) 내담자 중심치료, 3) 스트레스 개입, 4) 집단 마사지 요법, 5) 영적 최면 요법을 살펴보고자 한다.

애도와 트라우마 개입은 허리케인 카트리나(Katrina) 이후 Salloum과 Overstreet ${ }^{54,55}$ 가 보고하였다. Salloum과 Overstreet $^{54)}$ 는 허리케인 카트리나(Katrina) 사건에 노출된 7 12세 56 명의 소아청소년을 대상으로 실험군은 개인치료로 애도와 외상 다루기 개입(GTI-individual) 10회기를, 대조군은 집단치 료로 애도와 외상 다루기 개입(GTI-group) 10회기를 실시하 여 비교·분석하였다. 연구결과, 개인 및 집단 GTI 모두 소아 청소년의 재해 관련 노출, $\mathrm{PTSD}$, 우울 증상에서 유의한 호전 을 보였다. Salloum과 Overstreet ${ }^{55)}$ 는 허리케인 카트리나(Katrina) 이후, 6 12세 소아청소년 70명을 대상으로 애도와 트 라우마 개입(GTI with Coping Skills and Trauma Narrative Processing, GTI-CN) 11회기를 집단으로 실시하였다. GTI$\mathrm{CN}$ 은 대처기술과 외상 내러티브 처리 과정을 포함한 개입을
의미하며, 그 결과 스트레스 관련 증상 및 사회적 지원 요인이 유의하게 호전되었다.

Goodman 등 ${ }^{56)}$ 은 미국 9/11 테러 공격 당시 15세의 고등학 생을 대상으로 5 개월 동안 내담자 중심치료를 실시한 결과, 유의한 효과가 나타났다고 보고하였다.

Hardin 등 ${ }^{57)}$ 은 1989년 미국의 허리케인 휴고(Hugo)로 인 한 재난을 경험한 13 18세 소아청소년 1030명에게 재난에서 의 스트레스 개입(catastrophic stress intervention, CSI)을 3 년 동안 매년 3회기씩 집단으로 시행하였다. CSI는 소아청소 년의 스트레스에 대한 이해를 통해 자기효능감과 사회적 지원 을 강화하는 프로그램으로, 이를 시행한 결과 자기효능감, 사 회적 지원에서 유의한 호전이 있었다.

1992년 허리케인 앤드류(Andrew) 발생 이후 Field 등 ${ }^{58}$ )은 12 세 소아청소년 60명에게 집단 마사지(massage)요법 8회기를 실시하였다. 개입 이후, RCMAS 척도를 통해 불안 증상의 호전 및 타액 코티졸 수치를 감소시키는 데 유의한 효과가 있었다.

Lesmana 등 ${ }^{59}$ 은 2002년 인도네시아 발리에서 테러 공격을 경험한 6 12세의 소아청소년 226명을 대상으로 영적 최면 요법(spiritual hypnosis)을 실시하였고, 사전·사후 연구결과 $\mathrm{PTSD}$ 증상이 유의하게 호전되었다(부록 8).

\section{특정 지역사회나 학교 등에 대한 특화된 개입}

특정 지역사회나 환경을 대상으로 하거나 학교라는 특정한 개입 공간을 통하여 진행하는 개입을 살펴보기로 한다.

\section{프로젝트 개입(Project intervention)}

프로젝트 개입은 지역사회를 기반으로 이루어진 외상 반응 교육, 위기 상담, 캠프, 개인 및 집단치료, 약물치료 등의 요소 들이 포함된 종합적인 접근 방식의 정신건강 서비스이다. 이와 관련하여 Baton Rouge Children's Health Project(BRCHP), Project Liberty, Carolina Adolescent Health Project(CAHP), Project Hope를 소개하고자 한다.

첫째, Madrid 등 ${ }^{60)}$ 은 2005년 허리케인 카트리나(Katrina) 발생 당시 BRCHP를 실시하였다. BRCHP는 배턴루지(Baton Rouge) 어린이 건강 프로젝트를 의미하며, 놀이치료와 예술 치료를 포함한 개인치료, 이완 훈련, 내담자의 강점을 활용한 대처전략 교육, 또래와의 경험을 공유하여 고립을 감소시키는 집단치료, 난민 아동을 위한 캠프, 중등도 이상의 증상(과잉 행동, 불안, 우울) 관리를 위한 약물치료, 학교 및 지역사회 기 반 활동, 사례관리 등의 개입으로 구성되어 있다. 이는 정신건 강전문가와 교사가 개입함으로써 자연 재해 이후 피해 당사 자에 대한 의료 및 정신건강서비스의 주요한 가치와 필요성을 입증하였다. 
둘째, Felton ${ }^{61)}$ 은 2001년 미국 9/11 테러 사건 이후 2004년까 지 자유 프로젝트(Project Liberty)를 실시하였다고 보고하였 다. 이는 PTSD를 완화하기 위해 소아청소년을 포함한 지역사 회주민을 대상으로 한 대규모 공중 보건 개입으로, 총 42025 명이 참여하였으며, 위기 상담을 받은 대상자들은 슬픔(39\%), 불안/두려움(33\%), 불면(24\%), 과민성/분노(22\%), 집중의 어려 움(20\%) 등의 문제를 호소하였다. 자유 프로젝트는 이들에게 외상 반응에 대한 교육 및 위기 상담 서비스를 제공하였으며, 사고 직후부터 지역사회에 널리 구현되어 지역 정신건강 시스 템으로의 역할을 수행하였다.

셋째, Stewart 등 ${ }^{22)}$ 은 1989년 허리케인 휴고(Hugo) 재난을 경험한 13 17세 소아청소년 259명에게 캐롤라이나 주의 청소 년을 위한 건강 프로젝트(CAHP) 1회기를 실시하였다. CAHP 는 개인치료와 집단치료를 병행한 인지적 사회 지원(cognitive social support, CSS) 집단 프로토콜로서, 참여자의 $82 \%$ 가 설 문을 통해 $\mathrm{CSS}$ 의 구조, 내용, 과정 등에 대해 우수하다고 평 가하였다. 또한 청소년을 위한 사회적 지원이 스트레스를 완 화시켰으며, 심리적 증상에서도 유의한 효과가 있었다.

넷째, 2012년 발생한 허리케인 샌디(Sandy) 재난 이후 2014 년까지 희망 프로젝트(Project Hope) ${ }^{63}$ 가 보고된 바 있다. 이 는 사건을 경험한 약 40 만 명의 소아청소년과 지역 주민을 대 상으로 하였으며, 학교, 종교 및 지역사회 기관, 가정 내 다양 한 장소에서 지역사회 기반의 위기 상담이 제공되었다. 희망 프로젝트는 개인 및 집단 상담, 공공 교육, 자원 연계, 정신건 강 및 약물 정보 서비스, 핫라인 위기 서비스 등의 요소로 구 성되었으며, 스트레스 관리 및 대처 전략 개발, 역량 강화, 회 복 촉진에 도움을 주고자 하였다. ${ }^{61)}$

근거 기반의 프로젝트 개입은 재난 이후 지역사회에서 가 능한 자원을 충분히 활용하였고, 여러 직역의 전문가가 함께 재난 극복을 위해 기여하였다(부록 9).

\section{학교기반 개입(School-based intervention)}

학교는 지역사회 내에서 정신건강 서비스 제공이 가능하며 소아청소년이 쉽게 접근할 수 있는 환경이다. ${ }^{64)}$ 학교기반 개입 은 재난과 외상 노출에 대처할 수 있도록 고안된 교실 기반 프 로그램으로, 외상을 경험한 소아청소년의 정상화를 돕고 또 래와의 상호작용 및 긍정적인 심리적 안정감 향상을 도와 회 피와 고립 증상을 완화시킨다. 대표적인 프로그램으로는 1) enhancing resiliency amongst students experiencing stress (ERASE-Stress), 2) Cognitive behavioral intervention for trauma in schools(CBITS), 3) support for students exposed to trauma(SSET), 4) school therapeutic enhancement pro$\operatorname{gram}(\mathrm{STEP}), 5)$ 기타 보고 등을 들 수 있다.
스트레스를 경험한 소아청소년의 탄력성 강화 치료 개입

(Enhancing resiliency amongst students experiencing stress, ERASE-Stress)

이스라엘에서 2000년부터 2008년까지의 만성적 테러 사건 에 대해 Berger 등 ${ }^{65)}$ 은 11 13세 소아청소년 154명을 대상으 로 스트레스를 경험한 소아청소년의 탄력성 강화 치료 개입 (ERASE-Stress) 16회기를 집단으로 시행하였다. ERASEStress 시행 결과, 연구 대상의 PTSD, 불안, 기능장애, 신체증 상에서 모두 유의하게 개선되었다. 2000년부터 2006년까지 이스라엘 내 다수 테러 공격을 포함한 재난에 관한 연구 ${ }^{60}$ 에 서는 ERASE-Stress 프로그램을 학교 교육과정의 일환으로 담임교사가 매 회기 90분씩 12회기를 집단으로 실시하였다. 개입 결과 외상 관련 증상을 호소하는 소아청소년의 부정적 인식이 유의하게 개선되었다.

스리랑카에서는 인도양 지진 해일 발생 이후 9 14세 소아청 소년 166명을 대상으로 학교기반 ERASE-Stress-Sri Lanka (ES-SL) 프로그램을 12 주간 적용한 연구 ${ }^{67}$ 가 있었다. 무작위 대조군 연구로서 개인치료와 집단치료를 병행하였고 부모가 참 여하였으며, 이에 대한 결과로 소아청소년의 PTSD 심각도, 기 능장애, 우울, 신체증상 등 모든 변수가 유의하게 개선되었다.

학교 내 외상에 대한 인지행동 개입(Cognitive behavioral intervention for trauma in schools, CBITS)

CBITS는 근거 기반의 단기 그룹 인지행동치료 프로그램으 로서 소수 인종 및 다양한 외상에 노출된 청소년의 부정적인 영향을 감소시키기 위해 개발되었으며, ${ }^{68)}$ 부모 참여 회기 및 교사 교육을 포함한다. ${ }^{6} \mathrm{Ngo}$ 등 ${ }^{68)}$ 은 중학생 6 명을 대상으로 $\mathrm{CBITS}$ 를 실시하여 긍정적인 효과를 보고하였고, Macy 등 69 의 연구에서는 1999년 발생한 터키 지진 사건 이후, 초등학생 과 고등학생 484명을 대상으로 교실 기반 개입(classroombased intervention, $\mathrm{CBI}$ ) 3회기를 집단으로 실시하였다. 특 히 $\mathrm{CBI}$ 에서는 소아청소년이 자신의 이야기를 직접 표현하도 록 돕고, 집단환경에서의 대처 전략 개발 및 안전한 장소 구 축을 위한 특정 주제를 강조하였으며, 부모가 자녀 숙제에 함 께 참여하였다. 또한 Morsette 등이는 6 12세 소아청소년 7 명을 대상으로 한 연구에서 10주의 집단 CBITS를 시행하였으 며, 소아 PTSD 증상 척도(The Child PTSD Symptom Scale, $\mathrm{CPSS}), \mathrm{CDI}$ 척도 평가 결과, $\mathrm{PTSD}$ 및 우울 점수가 감소되어 유의한 호전을 보였다 $(\mathrm{p}<0.001)$.

외상에 노출된 학생 지지하기 프로그램(Support for students exposed to trauma, SSET)

SSET는 외상에 노출된 학생을 대상으로 한 구조적 접근 방 
식의 개입으로, $\mathrm{PTSD}$ 증상의 감소와 $\mathrm{PTSD}$ 와 관련 문제의 완화, 회복력 구축, 친구와 부모의 지원 구축을 목표로 하는 프로그램이다. ${ }^{71)}$ 교사 및 상담교사가 시행하며, 스트레스나 외 상 반응에 대한 심리교육, 이완 훈련, 생각과 감정에 대한 인 지적 대처, 불안과 외상 기억으로의 점진적 접근, 외상 기억 처리, 사회적인 문제 해결 요소2)를 포함한 총 10 회기로 구성 되었다.

Jaycox 등 ${ }^{22)}$ 은 아동 학대에 노출된 중학생과 부모 78 명을 대상으로 SSET 개입에 관한 예비연구를 실시하였고, 3개월 과 6개월의 추적관찰 결과, 인생 경험 설문 수정판(The Modified Life Experiences Survey), 강점과 약점 설문 평 가-부모 및 교사 보고(Strengths and Difficulties Questionnaire-Parent Report, and Teacher Report), CDI 척도, CPSS 척도 평가를 통해 학생들의 심리적 증상에 대한 유의한 호전 을 보였다. SSET 프로그램은 학생과 부모 모두 높은 만족도 를 보였으며, 이는 재난 현장에서의 효과적인 학교 상담 개입 으로서 구현 가능함을 시사하였다.

학교기반 치료적 향상 프로그램(School therapeutic enhancement program, STEP)

2005년 허리케인 카트리나(Katrina) 피해 이후 Goldman 등 ${ }^{33)}$ 은 386 명의 중학생과 고등학생에게 학교기반 치료적 향 상 프로그램(STEP)을 실시하였다. STEP 집단 프로그램은 8 회기 또는 12 회기로 진행되었고, 부모가 참여하였다. 개입 이 후 소아청소년의 스트레스 수준이 유의하게 개선되었으며, 자 연 재해의 여파로 정신적 어려움을 겪는 소아청소년을 위한 학교기반 개입의 효과를 입증하였다.

기타 보고

Goenjian 등 ${ }^{74)}$ 은 1988년 아르메니아(Armenia) 지진으로 발생된 피해자 64명에게 학교기반 정신건강 개입을 시행하였 다. 이는 외상/애도에 초점을 둔 심리치료 개입으로, 재해를 경험한 청소년의 PTSD 증상 완화를 목적으로 하였다. 개인 치료와 더불어 부모가 참여한 집단치료를 병행하였으며, 사 전·사후 연구결과 우울 및 $\mathrm{PTSD}$ 증상을 감소시키는 데 효과 가 있었다. Weems 등 ${ }^{75)}$ 은 허리케인 카트리나(Katrina) 재난 을 경험한 13 16세 소아청소년 94명을 대상으로 학교 기반의 시험 불안을 주제로 한 개입(school-based test anxiety intervention)을 4 5주간 5회기를 집단으로 실시하였으며, 높은 시험 불안 증상과 학업성적에서 상당한 효과가 있었다.

앞서 심리교육에서 언급한 Brown 등흐는 2001년 미국 9/11 테러 사건 이후, 8 13세 소아청소년 64명에게 10회기의 학교 기반 외상 특정 개입(school-based trauma-specific inter- vention)을 실시한 결과, PTSD, 불안, 우울 증상에서 효과가 있었다. 그리고 Berger 등 ${ }^{64)}$ 의 연구에서는 테러노출 방지 및 $\mathrm{PTSD}$ 관련 증상, 신체 증상, 기능 장애 및 불안 증상을 감소 시키기 위한 교실 기반 개입을 실시하였다. 한편, 2000년부터 2003년까지 이스라엘의 자살 폭탄 테러를 포함한 재난을 경 험한 6학년 학생 총 142 명에게 테러 노출자 대상 프로그램 (objective exposure to terrorism, OTT)을 시행하였고, 이는 학교 교육 과정으로 도입되었다. OTT는 8회기로 구성된 집단 프로그램으로 워밍업, 집단 작업, 심리교육, 대처기술훈련, 숙 제 안내 등의 요소로 구성되었으며, 개입 1년 후 추적관찰 결 과, PTSD 증상의 유의한 호전을 보였다. 또한, 2006년 2차 레 바논 전쟁 이후 8 12세 소아청소년 2135명을 대상으로 한 연 구기에서는 개인의 탄력성 강화에 초점을 둔 교사 개입 프로 그램 16 회기를 진행한 바 있으며, 3 개월의 추적관찰 결과 심 리적 증상 및 적응 기능 요인에서 유의한 효과가 있었다고 보 고하였다.

이 외에도 Wolmer 등 ${ }^{78)}$ 은 1999년 터키 지진 당시, 202명의 소아청소년에게 학교 활성화 프로그램(School Reactivation Program)을 집단으로 적용하였고, 2008년 중국 쓰촨 지진 발생과 관련하여 Wong $\mathrm{W}^{79)}$ 은 라농(Ranong) 지방에서 중학생 140 명을 대상으로 정신건강전문가가 학교 사회복지서비스를 개입한 바 있으며, 그 결과 재해 발생 이후 소아청소년의 심리 적 회복 가능성을 시사하였다.

한편 이스라엘에서는 예방적 개입도 연구되었다. 테러를 대 비하는 사전 개입 연구 ${ }^{80}$ 로 교사와 학교 관계자가 1488 명의 소아청소년에게 14 주의 프로그램을 실시한 결과, PTSD-RI 척도 및 스트레스/감정 척도(Stress/Mood Scale) 평가를 통 해 PTSD 증상에서 유의한 호전을 보였다 $(\mathrm{p}<0.001)$ (부록 10).

\section{웹 기반 개입(Web-based intervention)}

웹 기반 개입은 소아청소년의 재난 이후 정신건강과 위험에 대한 교육 내용 보급을 위해 구성되었다. 참여자들에게는 웹 사이트에 접근할 수 있는 지침을 제공하고, 고유한 사용자 ID 를 할당하며, 비디오 클립, 프레젠테이션 등 다양한 형식의 디 자인 그래픽을 사용한 웹 접근 방식을 활용한다. ${ }^{81)}$ 또한 소아 청소년의 발달 단계를 고려하여 적절한 어휘를 사용하고, 활 발한 상호작용을 위해 게임과 퀴즈와 같은 내용을 포함한다. Ruggiero 등 ${ }^{82}$ 의 연구에서는 토네이도 사건 발생 이후, 소아 청소년 2000명에게 웹 기반 개입(bounce back now, BBN) 프 로그램을 실시하였다. $\mathrm{BBN}$ 은 정신건강전문가와 자원봉사자 가 지역사회기관에서 집단으로 개입한 프로그램으로 연구결 과, $\mathrm{PTSD}$ 와 우울 증상을 포함한 재난 후 정신건강 장애 유병 률을 감소시키는 데 효과가 있었으며, 광범위한 접근, 비용의 
효율성 및 재난 현장에서의 실현 가능성을 시사하였다. 또한 $\mathrm{BBN}$ 개입과 더불어 성인 스스로를 돕는 모듈(adult self help modules)을 함께 적용한 연구 ${ }^{81}$ 가 보고되었다. 이는 소아청소 년 2000명이라는 연구 대상 수는 동일하나, 개별치료가 시행 되었다는 점과 부모가 치료에 개입한 부분이 달랐다. 이에 대 한 결과로 $\mathrm{BBN}$ 은 재난 후 소아청소년을 위한 정신사회적 개 입으로서 치료적 효과의 타당성을 보고하였으며, 웹 기술 기 반 솔루션의 잠재적 가치를 입증하였다(부록 11).

\section{고 찰}

국외의 정신건강의학 데이터베이스 검색을 통해 재난 연구 에 관한 체계적 문헌고찰을 시행하였다. 재난 후 소아청소년 을 대상으로 정신사회적 개입 연구를 분석하여 살펴본 사항 은 다음과 같다.

국외에서의 대표적 재난 사건으로는 1988년 주피터(Jupiter) 선박사고, 1989년 허리케인 휴고(Hugo), 1999년 대만 지진, 1999년 터키 마르마라(Marmara) 지진, 2001년 9/11 테러 공 격, 2005년 허리케인 카트리나(Katrina), 2008년 중국 쓰촨 지 진 등이 있었다. 이외에 화산폭발, 화재, 교통사고, 또래자살, 성폭행, 교통사고, 학교 인질극 등의 사건이 발생한 바 있으며, 이러한 일과성 대형 재난과 그 밖의 사건 등에서 적용한 개입 근거들을 분석하였다. 치료적 개입으로는 $\mathrm{PFA}$, 심리적 디브 리핑, 심리교육, TF-CBT, EMDR, PE, 집단 놀이치료 및 예술 치료, 프로젝트 개입, 학교기반 개입, 웹 기반 개입 등이 있었 으며, 선진국에서의 보고와 그 외 나라에서의 보고, 분쟁지역 에서의 보고 등으로 살펴볼 수 있었다. 이에 대한 연구들은 단일 개입, 대조군 연구, 사전-사후 비교 연구 등에 따른 연구 방법이 상이하였으며, 재난의 종류나 시기가 달라 개입의 효 과를 비교하여 단일한 결론을 도출하는 데는 어려운 부분이 있었다.

그럼에도 유의한 근거가 여러 재난 및 트라우마 현장에서 일관되게 보고되는 정도와 미국 소아청소년정신의학회 (American Academy of Child and Adolescent Psychiatry) 에 명시되어 있는 소아청소년 PTSD 실무 지침 가이드라인3) 을 참고로 하여 효과성이 보고된 개입들을 아래와 같이 분류 할 수 있었다. 재난과 트라우마 이후 1) 가장 많은 유의한 효과 와 근거가 보고되는 개입 방법은 $\mathrm{TF}-\mathrm{CBT}$ 이다. 이는 대다수 의 재난과 트라우마 현장에서 유익할 것으로 보인다. 2) PFA 와 심리교육도 유의한 근거를 보고하고 있다. 이 역시 대다수 의 재난과 트라우마 현장에서 유익할 것으로 보인다. 3) 소아 청소년에서 유의한 효과가 보고되고는 있으나 재난과 트라우 마 현장에서 보편적으로 적용하기를 권장하기에는 근거가 아
직 부족한 개입 방법으로는 $\mathrm{EMDR}, \mathrm{PE}$, 집단 놀이치료 및 예술치료를 들 수 있다. 4) 유의한 효과가 보고되고는 있으나 이의 효과에 대하여 신중하게 고려하여야 할 개입으로 심리 적 디브리핑을 들 수 있다. 5) 특정 지역사회나 학교를 대상으 로 하는 개입은 현재까지 문헌 조사상 근거 기반이 높은 순으 로 학교기반 개입, 프로젝트 개입, 웹 기반 개입으로 분류할 수 있겠다(Table 2).

요약하면 재난 후 소아청소년에서 가장 권장되는 개입은 TF-CBT이다. TF-CBT는 CBITS, TF-EICBI 등으로 응용되 어 보고된 바 있으며, 테러 공격, 허리케인, 지진, 공장 폭발사 고, 쓰나미, 화산폭발 등 재난 발생 이후에 개인치료, 집단치 료, 개인치료 및 집단치료를 병행한 구성, 부모 참여 등 다양 한 접근 연구들로 살펴볼 수 있었다. 이는 TF-CBT가 성적 학대, 우울증 등 심리적 외상에 노출된 소아청소년 대상에게 유의한 효과가 있음을 보고한 연구 ${ }^{84}$ 와 일치하며, 외상 충격 을 경험한 소아청소년에게 제공 가능한 증거 기반 치료로서 의 지속적 연구가 필요함을 확인하였다.

$\mathrm{TF}-\mathrm{CBT}$ 보다 출판된 효과성에 대한 보고는 아직 부족하나, 재난과 트라우마 이후 일반적으로 적용을 권장할 수 있다고 판단되는 개입 방법은 $\mathrm{PFA}$ 와 심리교육이다. $\mathrm{PFA}$ 는 재난 시 대 처 가능한 방법을 이해하도록 돕고, 민감한 재난 정보들을 널 리 구현할 수 있는 개입이다. 이는 허리케인 구스타프(Gustav) 와 아이크(Ike)에 노출된 소아청소년과 성인을 대상으로 PFA 를 시행한 결과, 생존자들의 재난 대응을 가능케 하고 응급 상황에서의 적절한 심리 개입으로서 효과를 나타낸 연구 ${ }^{85}$ 결

Table 2. Children in disaster: evaluation and recovery guideline version 1.0

\begin{tabular}{ll}
\hline \multicolumn{1}{c}{ Classification } & \multicolumn{1}{c}{ Intervention } \\
\hline $\begin{array}{c}\text { Intervention type } \\
\text { Cluster } 1 \text { (highly } \\
\text { recommended) }\end{array}$ & TF-CBT \\
Cluster 2 (recommended) & PFA \\
& Psychoeducation \\
Cluster 3 (occasionally & EMDR \\
recommended) & PE \\
& Group play therapy and arts \\
& therapy \\
Cluster 4 (if needed) & Psychological debriefing \\
Site specific program & \\
Evidence based & \\
High & School-based intervention \\
Middle & Project intervention \\
Limited & Web-based intervention \\
\hline
\end{tabular}

TF-CBT: trauma focused CBT, PFA: psychological first aid, EMDR: eye movement desensitization reprocessing, PE: prolonged exposure therapy 
과와도 합치되는 소견이다. 심리교육은 재난 이전 위험 대비 교육과 재난 발생 이후 개입으로 각각 시도되었다. 재난을 경 험한 소아청소년에게 PTSD 증상에 관한 심리교육은 필수적 이며, 호흡과 이완 교육 등을 통해 외상 증상의 안정화와 정 상화를 촉진시킨다는 연구 ${ }^{41)}$ 소견과도 상당 부분 일치한다.

$\mathrm{TF}-\mathrm{CBT}$ 와 PFA, 심리교육 외에 치료적 효과가 있을 것으 로 예견되나, 아직 소아청소년에서의 효과성에 대한 보고가 충분하지 않아 통상적으로 권장되지는 않고 필요한 경우 적 용할 수 있는 개입 방법이라고 판단된 것은 $\mathrm{EMDR}, \mathrm{PE}$, 집단 놀이치료 및 예술치료이다. EMDR은 허리케인, 지진 발생 이 후 3 주간의 단기 개입부터 1년 이상의 장기 개입으로 보고되었 다. 이는 PTSD로 진단된 소아청소년 33명을 대상으로 EMDR 의 변형된 프로토콜을 실시하여 PTSD와 연관된 재경험 증 상에서 유의한 호전을 보였다고 입증한 이전 연구 ${ }^{86}$ 와 일치한 다. $\mathrm{PE}$ 는 $\mathrm{PE}$ 단독개입, $\mathrm{PE}$ 와 이야기 치료를 병행한 개입, 정 신건강전문가가 개입한 집단치료로 제공된 바 있으며, 노출치 료를 통해 PTSD 환자의 공포증이 완화되어 그 효과를 검증 한 연구 ${ }^{47}$ 와도 맥을 같이 한다. 또한 집단 놀이치료 및 예술치 료는 외상을 경험한 소아청소년에 있어 언어표현 능력의 제한 으로 인한 치료적 개입의 어려움을 방지하고 개인의 성장과 회복에 초점을 둔 개입임을 보고한 연구 ${ }^{50}$ 와도 합치되는 소견 이다. 안전한 공간에서 비언어적으로 자신의 경험을 표현하기 를 선호하는 소아청소년의 경우, 외상 기억과 감정을 상징적 인 예술 활동으로 탐색하는 과정이 효과적일 수 있다고 판단 된다. 그러나 EMDR, PE 및 집단 놀이치료 및 예술치료에 대 한 소아청소년을 대상으로 한 개입 연구 보고는 일반적으로 권장하기에는 근거가 부족하다고 볼 수 있으며 향후 이에 대 한 효과성 연구가 더 필요하다.

심리적 디브리핑의 경우 효과가 보고되고는 있으나 그 효과 에 대해 좀 더 신중하게 고려하여야 할 개입으로 생각된다. 심 리적 디브리핑은 소규모 재난에서부터 일과성 대형 재난에 이르기까지 포괄적 접근을 시도하였다. 교통사고 피해자를 대 상으로 디브리핑을 적용한 연구결과, $\mathrm{PTSD}$ 와 우울 증상이 유의하게 호전되었으나, 일반적 의료 처치를 받은 대조군과 통 계적으로 유의한 차이가 없었다는 연구 ${ }^{52}$ 가 보고된 바 있다. 그러므로 향후 소아청소년 대상의 심리적 디브리핑 위기 개입 에 대한 경험적 분석 연구 및 고찰이 요구되며, 이는 여전히 논의해야 할 부분이다.

이외에도 개입 장소에 따른 분류 중 가장 근거가 높다고 볼 수 있는 학교기반 개입은 대형 재난 사건 발생 이후의 집단 개입으로서 ERASE-Stress, ES-SL, CBITS, OTT, STEP, 학 교 활성화 프로그램 등의 접근 모델을 살펴볼 수 있었다. 학교 는 소아청소년에게 효과적인 접근 환경이지만 교내에서 개인
치료를 실시할 경우, 사적인 조용한 공간 확보가 어려웠음을 토로한 연구 ${ }^{41}$ 가 보고된 바 있으므로 이에 대한 실질적인 보 완 방식 또한 재고될 필요가 있다. 특히 학교는 소아청소년이 경험한 심리적 외상의 회복을 제공하는 유일한 통로임을 기억 해야 하며) 학교기반 개입의 접근환경, 치료 제공 기관 및 재 난심리지원전문가 구축, 부모 참여 등의 개입 방식을 구체화 할 것을 기대한다. 이를 통해 학교기반 개입은 재난을 경험한 소아청소년에게 효과적이며 실용적인 개입 방식으로서 매우 유용하다고 볼 수 있다. 또한 BRCHP, CAHP, Project Liberty, Project Hope 등의 프로젝트 개입은 보다 포괄적인 지역사회 와 여러 직역을 포함한 접근으로서 그 효과를 보고하였다. 새 로운 접근인 웹 기반 개입은 대규모 접근이 가능하다는 강점 을 시사하였으며, 인터넷과 스마트 폰 접속의 급속한 사회적 성장과 더불어 재난 이후 상황에서 효과적인 웹 메커니즘의 실현 가능성을 보여주었다. 추후 비용 효율적인 면에서 증거 기반의 정신사회적 개입을 제공할 수 있는 웹 기반 프로그램 의 광범위한 구현과 자원 제공을 기대한다. 이에 따라 국내에 서도 각각의 치료 방법뿐만 아니라 지역사회 기반의 프로젝 트 실행 및 프로세스를 계획하고 검증할 필요가 있다.

Lee 등)의 연구에 따르면, 재난 후 소아청소년 정신사회적 개입은 급성기의 PFA 개입에서부터 PTSD, 우울 증상과 같 은 정신과적 질환에 대한 정신치료에 이르기까지 다양한 접 근이 있음을 제시하였고, 국내에서도 재난을 경험한 소아청소 년에게 장기적 관점에서의 충분한 인력, 재원 확보, 거버넌스 구축을 위해 노력해야 함을 시사하였다. 본 논문에서는 소아 청소년을 대상으로 재난 이후 보고된 효과적인 개입 방법을 검토하였으며, 문헌 보고의 질과 양을 바탕으로 권장 수준을 분류하였다. 이를 토대로 우선순위를 고려하여 우리나라 문화 및 정서에 맞는 개입 방법을 개발하고 지속적으로 보완되어 야 할 것이다.

\section{결 론}

본 연구에서는 재난 후 소아청소년을 대상으로 정신사회적 치료 개입에 관한 체계적 문헌고찰을 실시하였다. 9/11 테러, 허리케인 카트리나(Katrina) 등 광범위한 지역사회 재난 후 개입 효과에 대한 체계적 문헌고찰을 통하여 근거 수준에 따 른 치료적 개입에 대한 우선 순위를 파악할 수 있었다. 재난 이후 소아청소년을 대상으로 여러 치료적 개입을 계획하고 시 행함에 있어 근거 수준을 점검하는 자료로도 활용할 수 있을 것으로 본다. 저자들이 판단한 바에 의하면, 재난 이후 통상 적으로 권고되는 $\mathrm{TF}-\mathrm{CBT}, \mathrm{PFA}$, 심리교육과 같은 개입의 경 우 이에 대한 국내 자료의 개발 및 보급이 우선적으로 필요할 
것이다. 소아청소년이 속한 학교와 지역사회 내에서 외상 경 험 회복을 위한 여러 직역과 자원을 아우르는 프로젝트 개입 과 같은 계획이 수립되는 것이 회복에 효과적일 것이며, 이와 관련된 인적·물적 자원 준비, 지역사회의 인프라 구축은 물 론 국가적인 정책 수립 등도 필요하겠다. 한편 외국의 문헌을 통해 근거를 확인하였으나 한국에서의 효과가 검증된 개입은 아직 보고가 거의 없다. 재난 이후 국내에서의 소아청소년에 대한 효과적인 개입이 지속적으로 검증되고 발전되기 위해서 는 현장 및 재난 이후 전문가들의 자료 수집과 사후 분석 및 연구에 대한 국민적 공감대의 형성 및 지속적인 인적 물적 자 원의 지원이 필요하며 이에 대한 공공의 제도적인 보완도 반 드시 고려되어야 한다.

중심 단어: 재난; 트라우마; 정신사회적 개입; 소아청소년; 체계적 문헌고찰.

\section{Acknowledgments}

본 연구는 보건복지부 정신건강기술개발사업의 지원에 의하여 이 루어진 것임(HM15C1058).

\section{Conflicts of Interest}

The authors have no financial conflicts of interest.

\section{References}

1) Breslau N, Kessler RC, Chilcoat HD, Schultz LR, Davis GC, Andreski P. Trauma and posttraumatic stress disorder in the community: the 1996 detroit area survey of trauma. Arch Gen Psychiatry 1998;55:626-632.

2) Committee DMH. Disaster and Mental Health. Seoul: Hakjisa;2015. p.201-214.

3) Cohen JA, Jaycox LH, Walker DW, Mannarino AP, Langley AK, DuClos JL. Treating traumatized children after hurricane Katrina: project Fleur-de lis. Clin Child Fam Psychol Rev 2009;12:55-64.

4) Jaycox LH, Cohen JA, Mannarino AP, Walker DW, Langley AK, Gegenheimer KL, et al. Children's mental health care following hurricane Katrina: a field trial of trauma-focused psychotherapies. J Trauma Stress 2010;23:223-231.

5) Newman E, Pfefferbaum B, Kirlic N, Tett R, Nelson S, Liles B. Meta-analytic review of psychological interventions for children survivors of natural and man-made disasters. Curr Psychiatry Rep 2014:16:462.

6) Lee CS, Seo JY, Park J, Chang HY, Bhang SY. Psychosocial intervention and practical experience in children and adolescent before and after a disaster. J Korean Neuropsychiatr Assoc 2015;54:276281.

7) Pfefferbaum B, Sweeton JL, Newman E, Varma V, Nitiéma P, Shaw JA, et al. Child disaster mental health interventions, part I: techniques, outcomes, and methodological considerations. Disaster Health 2014;2:46-57.

8) Pfefferbaum B, Sweeton JL, Newman E, Varma V, Noffsinger MA, Shaw JA, et al. Child disaster mental health interventions, part II: timing of implementation, delivery settings and providers, and therapeutic approaches. Disaster Health 2014;2:58-67.

9) Dieltjens T, Moonens I, Van Praet K, De Buck E, Vandekerckhove P. A systematic literature search on psychological first aid: lack of evidence to develop guidelines. PLoS One 2014;9:e114714.

10) Cain DS, Plummer CA, Fisher RM, Bankston TQ. Weathering the storm: persistent effects and psychological first aid with children displaced by hurricane Katrina. J Child Adolesc Trauma 2010;3: 330-343.

11) Plummer CA, Cain DS, Fisher RM, Bankston TQ. Practice challenges in using psychological first aid in a group format with children: a pilot study. Brief Treat Crisis Interv 2008;8:313-326.

12) Jacobs AK, Pfefferbaum B. The use of debriefing with children. Curr Psychiatry Rep 2015:17:40.

13) Stallard P, Velleman R, Salter E, Howse I, Yule W, Taylor G. A randomised controlled trial to determine the effectiveness of an early psychological intervention with children involved in road traffic accidents. J Child Psychol Psychiatry 2006;47:127-134.

14) Poijula S, Wahlberg KE, Dyregrov A. Adolescent suicide and suicide contagion in three secondary schools. Int J Emerg Ment Health 2001;3:163-168.

15) Stallard P, Law F. Screening and psychological debriefing of adolescent survivors of life-threatening events. Br J Psychiatry 1993; 163:660-665.

16) Vila G, Porche LM, Mouren-Simeoni MC. An 18-month longitudinal study of posttraumatic disorders in children who were taken hostage in their school. Psychosom Med 1999;61:746-754.

17) Yule W, Udwin O. Screening child survivors for post-traumatic stress disorders: experiences from the 'Jupiter' sinking. Br J Clin Psychol 1991;30(Pt 2):131-138.

18) Yule W. Post-traumatic stress disorder in child survivors of shipping disasters: the sinking of the 'Jupiter'. Psychother Psychosom 1992;57:200-205.

19) Pfefferbaum B, Jacobs AK, Nitiéma P, Everly GS Jr. Child debriefing: a review of the evidence base. Prehosp Disaster Med 2015;30: 306-315.

20) Ritchie EC, Watson PJ, Friedman MJ. Interventions following mass violence and disasters. New york: Guildford Press;2006.

21) Oflaz F, Hatipoğlu S, Aydin H. Effectiveness of psychoeducation intervention on post-traumatic stress disorder and coping styles of earthquake survivors. J Clin Nurs 2008;17:677-687.

22) Ronan KR, Johnston DM. Hazards education for youth: a quasiexperimental investigation. Risk Anal 2003;23:1009-1020.

23) Goenjian AK, Walling D, Steinberg AM, Karayan I, Najarian LM, Pynoos R. A prospective study of posttraumatic stress and depressive reactions among treated and untreated adolescents 5 years after a catastrophic disaster. Am J Psychiatry 2005;162:2302-2308.

24) Sahin NH, Yilmaz B, Batigun A. Psychoeducation for children and adults after the Marmara earthquake: an evaluation study. Traumatology 2011;17:41-49.

25) Vijayakumar L, Kannan GK, Ganesh Kumar B, Devarajan P. Do all children need intervention after exposure to tsunami? Int Rev Psychiatry 2006;18:515-522.

26) Berkowitz S, Bryant R, Biymer M, Hamblen J, Jacobs A, Layne C, et al. Skills for psychological recovery: field operations guide. White River Junction, VT: National Center for PTSD and National Child Traumatic Stress Network;2010.

27) Forbes D, Fletcher S, Wolfgang B, Varker T, Creamer M, Brymer MJ, et al. Practitioner perceptions of skills for psychological recovery: a training programme for health practitioners in the aftermath of the Victorian bushfires. Aust N Z J Psychiatry 2010;44:11051111.

28) Goldbeck L, Muche R, Sachser C, Tutus D, Rosner R. Effectiveness of trauma-focused cognitive behavioral therapy for children and adolescents: a randomized controlled trial in eight german mental health clinics. Psychother Psychosom 2016;85:159-170.

29) Ronan KR, Johnston DM. Behaviourally-based interventions for children following volcanic eruptions: an evaluation of effectiveness. Disaster Prev Manag 1999;8:169-176.

30) Karairmak O, Aydin G. Reducing earthquake-related fears in victim and nonvictim children. J Genet Psychol 2008;169:177-185. 
31) Giannopoulou I, Dikaiakou A, Yule W. Cognitive-behavioural group intervention for PTSD symptoms in children following the Athens 1999 earthquake: a pilot study. Clin Child Psychol Psychiatry 2006; 11:543-553.

32) de Roos C, Greenwald R, den Hollander-Gijsman M, Noorthoorn E, van Buuren S, de Jongh A. A randomised comparison of cognitive behavioural therapy (CBT) and eye movement desensitisation and reprocessing (EMDR) in disaster-exposed children. Eur J Psychotraumatol. 2011 Apr 6 [Epub]. http://dx.doi.org/10.3402/ejpt. v2i0.5694.

33) Naderi F, Alirezaie N, Yasami MT, Mohammadi MR, MahmoudiGharaei JMG, Moftakhari O. The effects of a short-term cognitive behavioral group intervention on Bam earthquake related PTSD symptoms in adolescents. Iran J Psychiatry 2009;4:79-84.

34) Shooshtary MH, Panaghi L, Moghadam JA. Outcome of cognitive behavioral therapy in adolescents after natural disaster. J Adolesc Health 2008;42:466-472.

35) Mahmoudi-Gharaei J, Mohammadi MR, Yasami MT, Josheghani N, Naderi F. Group cognitive-behavior therapy and supportive art and sport interventions on Bam earthquake related post traumatic stress symptoms in children: a field trial. Iran J Psychiatry 2009;4:85-91.

36) March JS, Amaya-Jackson L, Murray MC, Schulte A. Cognitivebehavioral psychotherapy for children and adolescents with posttraumatic stress disorder after a single-incident stressor. J Am Acad Child Adolesc Psychiatry 1998;37:585-593.

37) Brown EJ, Pearlman MY, Goodman RF. Facing fears and sadness: cognitive-behavioral therapy for childhood traumatic grief. Harv Rev Psychiatry 2004;12:187-198.

38) CATS Consortium. Implementation of CBT for youth affected by the World Trade Center Disaster: matching need to treatment intensity and reducing trauma symptoms. J Trauma Stress 2010;23:699707.

39) CATS Consortium. Implementing CBT for traumatized children and adolescents after september 11: lessons learned from the child and adolescent trauma treatments and services (CATS) project. J Clin Child Adolesc Psychol 2007;36:581-592.

40) Scheeringa MS, Weems CF, Cohen JA, Amaya-Jackson L, Guthrie D. Trauma-focused cognitive-behavioral therapy for posttraumatic stress disorder in three-through six year-old children: a randomized clinical trial. J Child Psychol Psychiatry 2011;52:853-860.

41) Taylor LK, Weems CF. Cognitive-behavior therapy for disaster-exposed youth with posttraumatic stress: results from a multiplebaseline examination. Behav Ther 2011;42:349-363.

42) Pityaratstian N, Liamwanich K, Ngamsamut N, Narkpongphun A, Chinajitphant N, Burapakajornpong N, et al. Cognitive-behavioral intervention for young tsunami victims. J Med Assoc Thai 2007; 90:518-523.

43) Leor A, Dolberg OT, Eshel SP, Yagil Y, Schreiber S. Trauma-focused early intensive cognitive behavioral intervention (TF-EIC$\mathrm{BI}$ ) in children and adolescent survivors of suicide bombing attacks (SBAs). A preliminary study. Am J Disaster Med 2013;8:227234.

44) Chemtob CM, Nakashima J, Carlson JG. Brief treatment for elementary school children with disaster-related posttraumatic stress disorder: a field study. J Clin Psychol 2002;58:99-112.

45) Fernandez I. EMDR as treatment of post-traumatic reactions: a field study on child victims of an earthquake. Edu Child Psychol 2007;24:65-72.

46) Grubaugh AL, Clapp JD, Frueh BC, Tuerk PW, Knapp RG, Egede LE. Open trial of exposure therapy for PTSD among patients with severe and persistent mental illness. Behav Res Ther 2016;78:1-12.

47) Foa EB, McLean CP. The efficacy of exposure therapy for anxietyrelated disorders and its underlying mechanisms: the case of OCD and PTSD. Annu Rev Clin Psychol 2016;12:1-28.
48) Gilboa-Schechtman E, Foa EB, Shafran N, Aderka IM, Powers MB, Rachamim L, et al. Prolonged exposure versus dynamic therapy for adolescent PTSD: a pilot randomized controlled trial. J Am Acad Child Adolesc Psychiatry 2010;49:1034-1042.

49) Catani C, Kohiladevy M, Ruf M, Schauer E, Elbert T, Neuner F. Treating children traumatized by war and tsunami: a comparison between exposure therapy and meditation-relaxation in NorthEast Sri Lanka. BMC Psychiatry 2009;9:22.

50) Rowe C, Watson-Ormond R, English L, Rubesin H, Marshall A, Linton K, et al. Evaluating art therapy to heal the effects of trauma among refugee youth: the Burma art therapy program evaluation. Health Promot Pract 2016 Mar 1 [Epub]. http://dx.doi.org/10.1177/ 1524839915626413.

51) Shen YJ. Short-term group play therapy with Chinese earthquake victims: effects on anxiety, depression and adjustment. Int J Play Ther 2002;11:43-63.

52) Zehnder D, Meuli M, Landolt MA. Effectiveness of a single-session early psychological intervention for children after road traffic accidents: a randomised controlled trial. Child Adolesc Psychiatry Ment Health 2010;4:7.

53) Thabet AA, Vostanis P, Karim K. Group crisis intervention for children during ongoing war conflict. Eur Child Adolesc Psychiatry 2005;14:262-269.

54) Salloum A, Overstreet S. Evaluation of individual and group grief and trauma interventions for children post disaster. J Clin Child Adolesc Psychol 2008;37:495-507.

55) Salloum A, Overstreet S. Grief and trauma intervention for children after disaster: exploring coping skills versus trauma narration. Behav Res Ther 2012;50:169-179.

56) Goodman RF, Morgan AV, Juriga S, Brown EJ. Letting the story unfold: a case study of client-centered therapy for childhood traumatic grief. Harv Rev Psychiatry 2004;12:199-212.

57) Hardin SB, Weinrich S, Weinrich M, Garrison C, Addy C, Hardin TL. Effects of a long-term psychosocial nursing intervention on adolescents exposed to catastrophic stress. Issues Ment Health Nurs 2002;23:537-551.

58) Field T, Seligman S, Scafidi F, Schanberg S. Alleviating posttraumatic stress in children following hurricane Andrew. J Appl Dev Psychol 1996;17:37-50.

59) Lesmana CB, Suryani LK, Jensen GD, Tiliopoulos N. A spiritualhypnosis assisted treatment of children with PTSD after the 2002 Bali terrorist attack. Am J Clin Hypn 2009;52:23-34.

60) Madrid PA, Sinclair H, Bankston AQ, Overholt S, Brito A, Domnitz R, et al. Building integrated mental health and medical programs for vulnerable populations post-disaster: connecting children and families to a medical home. Prehosp Disaster Med 2008;23: 314-321.

61) Felton CJ. Project liberty: a public health response to New Yorkers' mental health needs arising fromthe World Trade Center terrorist attacks. J Urban Health 2002;79:429-433

62) Stewart JB, Hardin SB, Weinrich S, McGeorge S, Lopez J, Pesut D. Group protocol to mitigate disaster stress and enhance social support in adolescents exposed to Hurricane Hugo. Issues Ment Health Nurs 1992;13:105-119.

63) Health NYC. Crisis/Emergency Services: Project HOPE [cited 2015 Jun 9]. https://wwwl.nyc.gov/site/doh/health/health-topics/ crisis-emergency-services-project-hope.page.

64) Berger R, Pat-Horenczyk R, Gelkopf M. School-based intervention for prevention and treatment of elementary-students' terror-related distress in Israel: a quasi-randomized controlled trial. J Trauma Stress 2007;20:541-551.

65) Berger R, Gelkopf M, Heineberg Y. A teacher-delivered intervention for adolescents exposed to ongoing and intense traumatic war-related stress: a quasi-randomized controlled study. J Adolesc Health 2012;51:453-461. 
66) Gelkopf M, Berger R. A school-based, teacher-mediated prevention program (ERASE-Stress) for reducing terror-related traumatic reactions in Israeli youth: a quasi-randomized controlled trial. J Child Psychol Psychiatry 2009;50:962-971.

67) Berger R, Gelkopf M. School-based intervention for the treatment of tsunami-related distress in children: a quasi-randomized controlled trial. Psychother Psychosom 2009;78:364-371.

68) Ngo V, Langley A, Kataoka SH, Nadeem E, Escudero P, Stein BD. Providing evidence-based practice to ethnically diverse youths: examples from the cognitive behavioral intervention for trauma in schools (CBITS) program. J Am Acad Child Adolesc Psychiatry 2008;47:858-862.

69) Macy RD, Macy DJ, Gross SI, Brighton P. Healing in familiar settings: support for children and youth in the classroom and community. New Dir Youth Dev 2003:51-79.

70) Morsette A, Swaney G, Stolle D, Schuldberg D, van den Pol R, Young M. Cognitive behavioral intervention for trauma in schools (CBITS): school-based treatment on a rural American Indian reservation. J Behav Ther Exp Psychiatry 2009;40:169-178.

71) Jaycox LH, Langley AK, Dean KL. Support for Students exposed to trauma: The SSET Program. Santa Monica: RAND Corporation;2009. p.3-187.

72) Jaycox LH, Langley AK, Stein BD, Wong M, Sharma P, Scott M, et al. Support for students exposed to trauma: a pilot study. School Ment Health 2009;1:49-60.

73) Goldman EE, Bauer D, Newman DL, Kalka E, Lochman JE, Silverman WK, et al. A school-based post-Katrina therapeutic intervention. Adm Policy Ment Health 2015;42:363-372.

74) Goenjian AK, Karayan I, Pynoos RS, Minassian D, Najarian LM, Steinberg AM, et al. Outcome of psychotherapy among early adolescents after trauma. Am J Psychiatry 1997;154:536-542.

75) Weems CF, Taylor LK, Costa NM, Marks AB, Romano DM, Verrett SL, et al. Effect of a school-based test anxiety intervention in ethnic minority youth exposed to hurricane Katrina. J Appl Dev Psychol 2009;30:218-226.

76) Brown EJ, McQuaid J, Farina L, Ali R, Winnick-Gelles A. Matching interventions to children's mental health needs: feasibility and acceptability of a pilot school-based trauma intervention program. Educ Treat Children 2006;29:257-286.
77) Wolmer L, Hamiel D, Barchas JD, Slone M, Laor N. Teacher-delivered resilience-focused intervention in schools with traumatized children following the second Lebanon war. J Trauma Stress 2011; 24:309-316.

78) Wolmer L, Laor N, Yazgan Y. School reactivation programs after disaster: could teachers serve as clinical mediators? Child Adolesc Psychiatr Clin N Am 2003;12:363-381.

79) Wong JH. Psychosocial recovery for children disabled in an earthquake: school social work in Dujiangyan, China. J Soc Work Disabil Rehabil 2013;12:102-115

80) Wolmer L, Hamiel D, Laor N. Preventing children's posttraumatic stress after disaster with teacher-based intervention: a controlled study. J Am Acad Child Adolesc Psychiatry 2011;50:340-348.

81) Ruggiero KJ, Price M, Adams Z, Stauffacher K, McCauley J, Danielson CK, et al. Web intervention for adolescents affected by disaster: population-based randomized controlled trial. J Am Acad Child Adolesc Psychiatry 2015;54:709-717.

82) Ruggiero KJ, Davidson TM, McCauley J, Gros KS, Welsh K, Price M, et al. Bounce back now! Protocol of a population-based randomized controlled trial to examine the efficacy of a web-based intervention with disaster-affected families. Contemp Clin Trials 2015; 40:138-149.

83) Cohen JA, Bukstein O, Walter H, Benson SR, Chrisman A, Farchione TR, et al. Practice parameter for the assessment and treatment of children and adolescents with posttraumatic stress disorder. J Am Acad Child Adolesc Psychiatry 2010;49:414-430.

84) Cohen JA. Treating traumatized children: current status and future directions. J Trauma Dissociation 2005;6:109-121.

85) Allen B, Brymer MJ, Steinberg AM, Vernberg EM, Jacobs A, Speier AH, et al. Perceptions of psychological first aid among providers responding to hurricanes Gustav and Ike. J Trauma Stress 2010; 23:509-513.

86) Ahmad A, Larsson B, Sundelin-Wahlsten V. EMDR treatment for children with PTSD: results of a randomized controlled trial. Nord J Psychiatry 2007;61:349-354.

87) Wolmer L, Laor N, Dedeoglu C, Siev J, Yazgan Y. Teacher-mediated intervention after disaster: a controlled three-year follow-up of children'sfunctioning. J Child Psychol Psychiatry 2005;46:11611168 . 